\title{
A Preparação de Servidores para o Serviço Público Brasileiro - A Escola de Serviço Público
}

35.082

\author{
WALDYR DOS SANTOS
}

Stella de Souza Pessanha

\author{
SUMÁRIO \\ I - O processo de industrialização do Brasil \\ II - Repercussão na Administração: a criação do Departamento Adminis- \\ trativo do Serviço Público \\ III - O problema de pessoal para a eficiência da Administração: a criação \\ dos Cursos de Administração \\ IV - A crise do sistema educacional de ǵrau médio \\ V - Ampliação do campo de ação dos Cursos de Administração como con- \\ seqüência \\ VI - A criação da Escola de Serviço Público
}

I

início do atual processo de industrialização do Brasil teve como causa preponderante a crise cambial conseqüente à depressão dos últimos anos da decada de 20.

Este fenômeno, que nos lançou na fase transitória que nos ccnduz ao pleno desenvolvimento e plena autonomia, refletiu-se $\epsilon \mathrm{m}$ todos os setores da vida do país, repercutindo expressivamente na administração pública.

Na superação da fase de subdesenvolvim€nto, tcrnou-se exigência imperiosa a exıstência de uma administração pública eficiente, isto é, do elemento que constitui a própria "medula do govêrno moderno: uma burocracia eficaz".

De fato, a própria situação de subdesenvolvimento cu de transição dessa fase para a industrialização, importando na exigüidade de capitais privados. faz do Estado o grande empreendedor.

Assim, a necessidade crescente de verđadeiro serviço público não poderia ser atingida pela máquina governamental que fôra constituída na fase de subdesenvclvimento ou semicolonialismo e que tinha as suas raízes na "politica de clientela", com tôdas as suas implicações. Chegamos, assim, ao primeiro grande "hiato cultural" dentre os vários que a crescente industrialização. do país nos iria criar: A função pública de que necessitava a sociedade brasileira não se harmonizava com o tipo de Estado existente. 
O aparelhamento administrativo, que se caracterizara, até então, por uma administração patrimonial, necessitava da racionalização de seus processos de ação pelas imposições da nova fase de desenvolvimento. Era indispensável que cs serviços públicos fôssem a expressão da capacidade do Estado em promover, organizar e corrigir.

A criação do Departamento Administrativo do Serviço Público, em 1938, constituiu fator primordial na revolução que se impunha na administração pública para sua perfeita sincronização com os novos quadros.

Órgão de "staff" da administração geral, no exercício dessa ampla função o D.A.S.P. vem provocando uma renovação sensível nos serviços públicos, orientando-os no sentido da sua racionalização.

III

Dentre os múltiplos setores que abrangem as atividades do D.A.S.P., avultam, pela sua capital importância, os problemas de pessoal, de vez que constitui ponto pacífico o fato de que "todo trabalho administrativo eficaz depende de que o pessoal que o realiza tenha sido recrutado e preparado de modo conveniente".

No exercício desta função particular o D.A.S.P. inclui, entre suas atribuições específicas, a seleção de pessoal, através da Divisão compətente, e os Cursos de Administração que se destinam ao aperfeiçoamento de servidores públicos, visando à formação profissional de administradores bem como ao treinamento e aperfeiçoamento de servidores públicos em geral.

Criados em 1940, pelo Decreto-lei n. ${ }^{\circ}$ 2.804, de 21 de novembro, os Cursos de Administração vêm mantendo cursos destinados a alcançar o objetivo mencionadc: o aperfeiçoamento dos servidores públicos.

Êsses cursos, em suas linhas gerais, enquadram-se na seguinte estrutura:

Administração Geral

Administração Especial

Atividades auxiliares da Administração

Os cursos abrangidos pela denominação "Administração Geral" constituem, a partir dêste ano de 58, o campo das atividades da Escola de Serviço Público, sôbre a qual nos estenderemos adiante.

Os cursos de Administração Especial destinam-se ao preparo de pessoal para serviços peculiares a determinados órgãos de ađministração.

Quanto aos cursos da terceira categoria, além de preparar pessoal para o exercício de atividades auxiliares da administração, têm ainda, por finalidade, suprir deficiências no preparo fundamental do servidor do Estado.

Através de quase 20 anos de atuação por meio dêsses cursos, cs C.A., em combinação com a Divisão de Seleção e como corolário ou decorrência

(1) CARL J. FrIEDRICH - "Teoria e Realidade da Organização Constitucional Democrática". 
do programa básico de racionalização do serviço público, vêm procurando extinguir o sistema de filhotismo que caracterizava o provimento dos cargos públicos, consequiência do mencionado "spoils system", herança dos processos de organızação administrativa do Império. Cada vez se va1 tornando menos significativo o provimento originado por êsse sistema de privilégios, pela concorrência no mercado de trabalho de elementos devidamente qualificados para as funções públicas.

\section{IV}

Acrescente-se que, além do descompasso assinalado entre as necessidades do país e a sua obsoleta máquina administrativa, a crise cambial conseqüente à 2. ${ }^{\text {a }}$ guerra mundial, dando novo e vigoroso impulso à nossa industrialização, veio pôr em evidência um outro "hiato cultural": a "décalage" entre essa industrialização crescente e o sistema educacional de grau médio.

É postulado estabelecido em Sociologia que "a gravidade da desorganização produzida no superorganismo pelos desiguais ritmos de mudança depende do grau de relação entre as diferentes partes". (2) E, considerando que desenvolvimento e educação constituem um binômio do forte interdependência no complexo cultural, somos conduzidos a reconhecer a gravidade do problema apontado.

De fato, o que se vem observando, nesse sentido, é o congestionamento do curso secundário pelo prestígio das "humanidades" - fenomeno que se liga às nossas tradições e origens culturais - em detrimento dos cursos técnicos, cujo desprestígio encontra suas raízes no preconceito contra o trabalho, característica da nossa tradição escravagista.

Esse desequilíbrio, cuja gravidede já foi assimilada pelos meios responsáveis pela educação do país, encontra sua expressão mais autorizada na observação contida no Pronunciamento do Ministério de Educação e Cultura sôbre o projeto de lei n. ${ }^{\circ} 2.222-57$ que fixa as Diretrizes e Bases da Educação Nacional.

Êsse Pronunciamento, expresso por Comissão constituida por educadores de renome nacional - Anísio Teixeira, Lourenço Filho, Pedro Calmon, Almeida Junior e FARia Góis - assim se manifesta a respeito do problema:

"Sendo incontestável o imperativo de formar técnicos para o desenvolvimento econômico do país, nota-se, entretanto, uma alarImante preferência dos jovens para o curso secundário, tradicionalmente prestigioso. Sâo, hoje, mais de 600 mil secundaristas para 18 mil alunos de escolas industriais. Isso, não obstante serem as escolas industriais gratuitas o seus cursos equivalentes aos do secundário, para acesso ao ensino superior."

(2) William F. OGburn e Meyer Nimkoff - Sociologia. 
E, a seguir, sugere a Comissão que se dêem os mesmos e prestigiosos nomes de ginásio e colégio aos cursos de igual nome nos diversos ramos porque, "além de prestigiar as atuais escolas profissionais aos olhos da sociedade, essa uniformidade da nomenclatura tornaria mais compreensível o sentido de equivaléncia dos cursos de grau médio, facilitando, também, a terminologia escolar e administrativa".

E o próprio Presidente da República, manifestando o pensamento das camadas esclarecidas da nação, assim se exprime ao referir-se ao ensino médio e ao traçar-lhe as metas:

“...o atual sistema educacional se mostra pouco apto a atrair a juventude brasileira para a modalidade de ensino que as conveniências do desenvolvimento econômico impõem imperativamente: formação de técnicos de nível médio para a indústria, comércio, agricultura e magistério prinário. Urge, assim, sejam reorganizados os cursos de modo a permitir a distribuição dos alunos de acôrdo com as aptidões, orientando-se para estudos predominantemente intelectuais apenas os que manffestarem essa vocação. Estes serão estimulados a ingressar em cursos superiores de natureza teórica, enquanto os demais serão encaminhados a ciencias aplicadas, em cursos de cunho acentuadamente prático. Uns e outros são igualmente necessários ao desenvolvimento nacional."

$\mathrm{E}$, mais adiante:

"Para corrigir tais falhas, decidiu o Govêrno adotar várias medidas, algumas das quais dependem da aprovaçăo de projetos de lei.

Ampla reforma foi pedida ao Legislativo, com relação ao ensino de grau médio, em todos os seus ramos, a fim de que os currículos se tornem mais flexíveis e ajustados às condições do País, tendo em mira as necessidades do desenvolvimento." (4)

Observe-se ainda que o Projeto que fixa as Diretrizes e Bases da Educação Nacional, como medida tendente a corrigir os males advindos de "aprêço mágico" em que é tida a escola secundária pelas camadas populares, estabelece para esta a diversificaçäo de cursos, concedendo-lhe maior flexibilidade e descentralização, em oposição à situação atual de rigidez de curriculos e centralizaçāo de podêres.

\section{V}

É é nesta conjuntura, criada pelo descompasso entre o ritmo em que se processa a nossa evolução para a fase tecnológica e o inadequado sistema escolar do pais, que o papel dos C.A., ultrapassando as suas finalidades próprias pelas contingências do momento nacional, vem assumir relevante importância.

De fato, sob a ação də organizações diversas e de grupos interessados, os C.A. foram compelidos a aceitar matrículas de alunos estranhos ao ser-

(3) Escola Secundária (n. 4) publicação da C.A.D.E.S. - M.E.C.

(4) Presidente JUSCELINo KUBITSCHEK - Mensagem ao Congresso Nacional na abertura da sessão leg slativa de 1958. 
viço público, vindo assim a exercer - mesmo fora dos quadros do funcionalismo - uma importante função de suplementação đo ensino técnico e especializado relacionado com a ciência da Administração.

Efetivamente, o mercado de trabalho do país - no comércio, na indústrıa, na admınistração -.- é influenciado pela carência, cada vez maior, de técnicos e auxiliares de nível médio - que é o nível da maioria dos cursos de formaçao, treinamento e aperfeiçoamento ministrados pelos C.A.

A aceitaçäo desta nova clientela que emprestou aos C.A. a atribuição de, eventualmente, preparar a treinar pessoal para emprêsas particulares, não importa em descumprimento de sua função, de vez que, tendo sido atingida a estrutura dos seus cursos e o seu programa de ação, veio atender a solicitações que encontram suas origens nas exigências surgidas do desenvolviments do país.

Assim, através de seus cursos planejados, inicialmente, ayenas para aperfeiçoamento do pessoal administrativo do Estado, vêm os C.A. prestando extraordinária colaboração às entidades que, tanto quanto o serviço público, riecessitam, para sua eficiéncia, de pessoal especializado, sobretudo no que concerne à ciência da Administração.

Além da constante elevada freqüência - também por alunos estranhos aos quadros do funcionalismo - dos cursos destinados "a suprir deficiências no preparo fundamental do servidor do Estado" (Português, Matemática) têm tido frequiência e êxito satisfatórios aquêles de caráter técnico e especializado, tais como os que mencionaremos a seguir e que constituem uma demonstração expressiva do papel de suplementação que vêm exercendo os C.A. face às deficiências repetidamente assinaladas do ensino dêste tipo no país.

A partir de 1940 mais de cem mil alunos (104.146) nêles buscaram formação, especialização ou aperfeiçoamento.

Relação de alguns cursos especializados ministrados pelos C.A.

(Sòmente foram incluídos na relação os que interessam, simultâneamente, a funcionários e elementos estranhos ao serviço público).

- Problemas de Administração de Material

- Problemas de Organização e Admiristração de Escritórios

- Higiene Mental

-. Sociologia

- Curso para Serventes e Mensageiros

- Preparação de Pessoal para Organização de Serviços

- Psicologia aplicada ao Trabalho

- Formação de Secretários

- Estatística aplicada à Administração

- Preparação de Taquígrafos

- Preparação de Almoxarife

- Fundamentos de Astronomia

-- Orientação, Seleção e Readaptação Profissional

- Princípios Gerais de Administração e Noções de Econonili

- Treinamento de Inspetores de Alunos 
- Relações Públicas

- Dactilografia

- Curso de Material

- Curso de Desenho

- Mecânica de Solos e Fundações

- Contabilidade

-- Economia Política

-- Direito Constitucional

- Princípios Gerais de Administraçãc e Racionalização do Trabalho

-... Mecanografia

-. Psicologia Social

- Fundamentos de Psicologia.

Vimos que os setores responsáveis pela eđucaçãu no pạis estäo plenamente esclarecidos quanto à desarmonia existente entre a superestrutura educacional e a estrutura social de que a primeira, em situação normal, deve ser projeção, para atender às suas finalidades profundas .

Providências vêm sendo tomadas (Lei de Diretrizes e Bases) no sentido de restabelecer o equilíbrio rompido pelo vigor do surto industrial.

A escola secundária, privilégio, até há pouco, das classes dcminantes, vinha absorvendo as classes populares, sem que o fenômeno fôsš acompanhado pela sua. democratização estrutural, exigência de sua nova posição.

Vamos sendo impelidos a democratizar a escola secundária na sua estrutura (fłexibilidade, descentralização) desde que a incorporação a ela de camadas populares sempre maiores - fruto imediato da crescente urbanização e de salários mais elevados - já a democratizou no sentido de que jả á estendeu a um maior número de indivíduos.

Por outro lado, vimos que as camadas responsáveis pela administraçāo pública já estão igualmente esclarecidas sôbre a necessidade de uma máquina administrativa eficiente, pela compreensão de que um serviço administrativo governamental permanente necessita de uma profunda preparação para enfrentar, de modo adequado, as funções governamentais de uma era industrial que cresce ràpidamente.

O reconhecimento da importância da ciência da Administração teve o seu bəneplácito oficial quando a Lei Orgânica do Ensino Comercial (Decretolei n. ${ }^{\circ} 6.141$ de 28 de dezembro de 1943) incluiu entre os cursos de segundo ciclo dêste ramo do ensino de grau médio o Curso Técnico de Administração.

E conveniente dar a éste fato o merecido relêvo pelo alto sentido que apresenta de esfôrço para suprir o país com elemento humano convenientemente preparado para o painel administrativo de suas atividades.

\section{VI}

A criação da Escola de Serviço Público assume, por fim, posição de culminância na multiplicidade de medidas para alcançar o objetivo tantas vêzes expresso neste trabalho.

Criada pelo Decreto n. ${ }^{\circ} 43.176$ de 4 de fevereiro de 1958, a Escola de Serviço Público veio a constituir-se dos Cursos de Administração Geral, 
a primeira das três categorias de cursos que integravam a estrutura geral clos C.A. (Administração Geral, Administração Específica e Atividades Auxiliares da Administração).

Funciona a Escola de Serviço Público em regime de acôrdo com o IVinistério de Educação e Cultura e o ensino nela ministrado será complemen tado, obrigatòriamente, por estágio no ambiente de trabalho das repartições.

Of́rece a Escola cursos de formação (Curso Técnico de Administraçäo e cursos de Aperfeiçoamento) além de cursos avulsos.

Prevê, ainda, o Decreto 43.176 a organização de cursos de especialização em grau superior para o preparo de técnicos de alto nível.

Neste primeiro ano de funcionamento, a Escola de Serviço Públicu vem mantendo os seguintes cursos:

\section{DE FORMAÇÃO}

A) Curso Técnico de Administração, com três anos de duração, é cursu integrante do $2{ }^{\circ}$ ciclo do Ensino Comercial e regido pela respectiva Lei Orgânica. Confere diploma de Assistente de Administração e - dentro dos limıtes de plasticidade conferidos pela La1 Orgànıca - sotrerá a influência da experiência dos C.A. em Ciêncra da Administração.

B) Cursos die Aperfeiçoamento

- Administração de Pessoal

- Administração Orçamentárıa

- Contabilidade Pública

- Correspondência e Estenodactilografia

- Correspondência e Redação Oficial

- Direito Usual

- Economia

- Finanças

- Organização de Serviços Públicos

- Relações Públicas

- Relações Humanas no Trabalho

- Sociologia

Foi pernitida a inscrição, em dois cursos apenas, como alunos regulares, dos candidatos que concluíram os cursos comerciais técnicos e, como alunos especiais, dos possuidores de diploma de curso superior, certificados dos antigos cursos de Administração Geral dos C.A., dos que exercem funções técnicas ou administrativas correlatas e de outros interessados que se sujeitassenı à prova de seleção de nível đo $2 .^{\circ}$ ciclo.

\section{DE ESPECIALIZAÇÃO DE GRAU SUPERIOR}

- Técnico de Pessoal

- Técnico de Organização

- Técnico de Orçamento

- Técnico de Educação 
Foì permitida a inscrição em apenas um dos cursos acinz e feita a exigência de títulos de nível superior.

O fatc de ter sido a Escola de Serviço Público instituída em regime de acôrdo com o Ministério de Educação e Cultura é do mais alto significado prático, cbjetivo e cultural.

A posição dos C.A. com vários anos de experiência no seu campo de ação tornou sobremodo aconselhável êsse compromisso entre as atividades de treinamento e aperfeiçoamento dos servidores do Estado e o sistema educacional do país.

Não nos parece inoportuno apresentar um prognóstico sôbre o futuro da Escola de Serviço Público. Vários fatôres nos autorizam a prever, com base segura, que será uma experiência bem sucedida.

São alguns dêsses fatôres:

a) a experiência dos C.A. no campo da divulgaçăo do ensino especializado e a possibilidade de valer-se das repartições públicas como Laboratório real das atividades administrativas;

b) a experiéncia geral do Ministério de Educação e Cultura, no que se refere ao problema do ensino e a sua autoridade como órgão supremo da educação no país;

c) o desenvolvimento crescente do Brasil em todos os setores, fazendo com que aumente, concomitantemente, o recrutamento, em nosso mercado de trabalho, de profissionais especializados;

d) á confiança que inspiram os C.A. à opiniāo pública pela categoria de seu corpo docente, pelos processos, orientação e qualidade do ensino ministrado e pela seriedade com que - há quase 20 anos - vêm realizando, exemplarmente, a sua tarefa.

\section{BIBLIOGRAFIA} crát:ca".

CARZ J. FRIEDRICH - "Teoria y rezlidad de la organizacion constitucional demo-

William F. O. G. BURn y MEYer F. Nimkoff - Sociologia.

Hélio JAGUARIBE - Condições Institucionais do desenvolvimento.

Geraldo Bastos Silva - Educação e desenvolvimento Nacional.

JAYME ABREU - A educação secundária no Brasil.

PRESIDENTE JUSCELINo KUBITSCHEK DE OliveIRA - Mensagem ao Congresso Nacional na abertura da sessão legislativa de 1958:

Desenvolvimento e conjuntura (N. $\left.{ }^{\circ} 1\right)-1957$.

Relatório das Atividades do D.A.S.P. - 1956.

Escola Secundária (n. ${ }^{\circ}$ ) - C.A.D.E.S.

Cadernos da C.A.E.C. (N. ${ }^{\circ}$ 1) - Cinqüentenário do Ensino Comercial.

Ensino Comercial - Boletim Informativo (N. $\left.{ }^{\circ} 2\right)$.

Ensino Comercial - Bo'etim Informativo (N. ${ }^{\circ} 3$ ).

Lei Orgânica do Ensino Comercial.

Lei Orgânica do Ensino Secundário.

Anuário Estatístico do Brasil 1956.

Boletim Mensal dos Cursos de Administração. 